\title{
The Discussing about Putting Eco-Agriculture into Practice in Taierzhuang District of Zaozhuang Municipality
}

\author{
Z.Y. Ding \\ School of Tourism, Resources and Environment, Zaozhuang University, Sandong Zaozhuang, 277160, China
}

\begin{abstract}
The condition of developing agriculture has advantageoues in Taierzhuang district of Zaozhuang municipality. But the traditional mode of agricultural production, there are a lot of drawbacks, the development of eco-agriculture is the route one must take the agricultural development in the area. According to the internal differences of the natural geographical environment, the corresponding eco-agriculture development models were proposed respectively. The hilly area of "ecological agriculture mode of forest shrub grass - livestock - Fishing - fruit grain"; northern plain area "planting-culture-processing-biogas-trade-tourism" the integration of ecological farm mode; the middle part of the area alonge the canal (Hanzhuang canal) and near the lake (Weishan Lake) to establish "dike pond marsh" model area of low-lying land.
\end{abstract}

Keywords - Taierzhuang District, Eco-Agriculture, Sustainable Development

\section{关于本庄市台儿庄区推行生态农业的探讨 \\ 丁兆运 \\ 本庄学院旅游与资源环境学院, 東庄, 山东, 中国}

摘 要 台儿庄区隶属于山东省本庄市, 发展农业的条件较为优越。但传统的农业生产方式存在很大的弊端, 发展生态农业是该 区农业发展的的必由之路。根据其自然地理环境的内部差异性，分别提出了相应的生态农业发展模式。即低山丘陵区的“林灌草-牧-渔 -果-粮”生态农业模式; 北部平原区的“种-养-加-沼-贸-旅”一体化的生态农场模式; 中部沿运（韩庄运河）滨湖（微山湖）洼地区建立“基 -塘-沼”模式。

关键词 台儿庄区, 生态农业, 可持续发展

\section{1. 引言}

生态农业是现代传统农业发展到一定阶段的产物，是 在人类根据生态学、经济学原理设计的, 由农业生物群体 与周围自然及社会经济环境组成的, 以太阳能高效转化获 取一系列农、畜产品为目的的人工生态系统。以机械化、 化肥化及农药化为主的现代农业在为人类带来丰富农产品 的同时, 也带来了诸如土壤污染、农业化学残留、农产品 品质下降、生物多样性减少等一系列生态环境问题, 限制 了农业的进一步发展。为解决农业生产本身所带来的环境 问题, 生态农业应运而生, 并受到了国内外专家、学者的 广泛关注。欧洲的生态农业兴起于 20 世纪 20 30 年代, 70 年代东南亚开始生态农业研究, 90 年代生态农业在世界范
围内得到发展 $[1]$ 。Z. Hochman 等对澳大利亚的农业生态集 约化进行研究, 力求使单位资源上生产出更多粮食的同时 减少粮食生产对环境的影响[2]。Quyet Manh $\mathrm{Vu}$ 等对人类 导致的生物生产力下降和他们的社会-生态类型对支持国 家政策和地方关于防治土地退化研究等热点问题进行了相 关探讨[3]。Ülo Mander 等对生态的和粗放农业作为对景观 及生物多样性的贡献者方面进行了研究, 结果显示了生态 农场对增加生物及景观多样性、减少养分及土壤流失方面 有显著意义[4]。Steven Archambault 研究了瑞典南部集约农 业所产生的营养盐和农药污染对波罗的海环境的影响, 确 定了几个重要的方面, 可以积极地鼓励在农业产业环境的 方法的进一步整合: 金融安全、扩大知识面、和当地的规 
划[5]。中国的生态农业始于 20 世纪 80 年代初, 对其研究 和实践已然成为当代中国农业发展的方向 [1]。骆世明划分 了生态农业存在的几种类型, 这种基本类型的区分有利于 认定生态农业建设的重点, 有利于模式改进、模式篮选和 推广、模式标准制定及模式的深入研究[6]。奉梅等对农业 循环经济的几种模式进行了比较, 认为选择正确的、适宜 的模式, 将使农村在循环经济这条道路上走得更远、更顺 畅[7]。刘兴等对中国新时期生态农业发展模式进行了相关 研究, 分析了中国生态农业发展的现状及其面临的困境与 挑战, 并提出了对策与建议[8]。李浩沝针对中国西南山区 生态农业的发展情况, 总结出了西南山区 4 种典型的生态 农业发展模式[9]。李轶等针对中国北方”四位一体”的农村 能源生态模式进行了能流定量分析并做出了系统评价[10]。 以上这些研究说明发展生态农业不仅能获取人类生存所需 要的健康食物, 而且还能保护环境, 是今后农业可持续发 展的必然选择。

\section{2. 研究区概况}

台儿庄区 $\left(117^{\circ} 23^{\prime} \sim 117^{\circ} 50^{\prime} \mathrm{E}, 34^{\circ} 28^{\prime} \sim 34^{\circ} 44^{\prime} \mathrm{N}\right)$ 为 莕庄市市辖区, 位于山东省的最南部, 东连沂蒙山, 西濒 微山湖, 南临交通枢纽徐州, 北接孔孟之乡曲阜。全区总 面积 $5.385 \times 104 \mathrm{hm} 2$, 辖 5 镇 1 街 1 个省级经济开发区, 211 个行政村 (居), 总人口 $3.1 \times 105$ 人。境内地势南北高, 中 间低, 自西向东渐低, 呈倾斜状, 北部为平原, 西南部为 连绵起伏的低山丘陵, 中部和东部较低洼; 台儿庄区属暖 温带大陆性季风气候区, 四季分明, 全年平均气温 $14^{\circ} \mathrm{C}$, 年平均降水量 $794 \mathrm{~mm}$, 年平均日照时数 $2182.3 \mathrm{~h}$, 无霜长; 全区可利用土地面积 4.33 万 $\mathrm{hm} 2$, 占土地总面积的 $81.16 \%$, 可耕地面积 3.78 万 $\mathrm{hm} 2$; 土壤共分为棕壤、褐土、潮土、 水稻土、砂姜黑土等五个土类, 土质和土壤性状偏好, 适 宜多种作物生长; 水资源较为丰富, 韩庄运河、伊家河、 大沙河、新沟河、胜利渠等纵贯全区, 以河水、湖水和井 水为主的三条农业生产供水水系, 可基本满足全区农业灌 溉需求。

\section{3. 台儿庄区农业发展存在的问题}

\section{1 种养结构较简单, 稳定性较差}

农业生态系统是受人类控制的以种植业为中心的生态 系统, 与自然生态系统相比, 其结构、功能、生产力等方 面已发生了巨大变化, 农作物品种是经过人工驯化培育的 生物品种, 抗逆性较差。本区耕作制度为一年二熟, 粮食 作物以小麦、玉米、水稻为主, 饲养的动物主要为猪、牛、 羊、鸡、鸭、鹅、淡水鱼类等。无论种植结构还是饲养结
构都较自然系统简单。食物链结构简单, 缺乏自然生态系 统所具有的复杂食物网关系, 抵抗自然灾害的能力较低, 农业生态系统的稳定性较差。

\section{2 农业污染较严重}

为了获得农业高产, 通常使用化肥补充土壤养分、喷 施农药杀灭害虫, 环境污染较严重。过量的养分进入地表 及地下水体导致水体发生一定的富营养化; 残留农药会随 着食物网转移, 发生毒物的生物富集, 影响食品安全, 威 胁人类的身体健康; 农业废弃物、人及动物的排泄物没有 有效地利用, 或焚烧, 或就地堆放, 经历风吹日晒及雨淋, 既造成巨大的资源浪费, 又污染环境, 农村的生活环境恶 劣。

\section{3 土壤退化, 水土流失较严重}

由于本区农业生产大多数情况仍采取传统的农耕方 式, 在收获种子的同时, 也将秸杆带出农田, 使土壤的物 质归还途径中断, 导致土壤有机质含量不断降低, 肥力持 续下降。本区的植被覆益率偏低, 水土流失现象较为严重, 导致一定的土壤侵蚀, 土壤耕作层减薄, 限制了农业的进 一步发展。

\section{4 理论基础不完备}

生态农业是一种复杂的系统工程, 它需要进行包括农 学、生态学、经济学、地理学、环境学等在内的多种学科 的综合研究。以前的研究, 往往注重农学或经济学的研究, 在应用中多看重作物的品种及产量的高低, 具有一定的片 面性, 由此带来一系列生态环境问题。因此, 需要进一步 从系统、综合的角度, 对生态农业进行更加深入的研究, 特别是要素之间的相互作用规律、结构的优化设计、科学 的分类体系、客观的评价方法方面。这种研究应当建立在 对现有生态农业模式进行深入的调查分析基础上，必须超 越农学、生态学、经济学之间的界限, 应当是多学科的交 叉与综合, 需要建立生态农业的自身的理论体系。

\section{5 农业科技人才不足, 生态意识较淡薄}

本区农业劳动者的整体文化水平偏低, 大多具有初中 及以下文化程度, 难以接受新的农业科学技术。农村的科 技人才也较缺乏, 导致农业新技术发明、创造较少, 农业 新技术的转化与推广的难度较大, 制约了本区农业较快、 较好的发展。尽管在局部区域开发了”三水农业”[11], ”观 光农业”, 取得了一定的经济生态效益, 人们对生态农业的 
观念有所认识和提高, 但劳动者整体的生态意识仍较淡薄, 大多数地区仍沿袭传统的农业生产方式, 经济效益不高, 环境问题较突出。

\section{4. 台儿庄区生态农业发展模式设计}

生态农业实质上是在吸收传统农业和现代农业优点的 基础上, 按照生态经济学原理和系统工程理论来组织实施, 通过农业生物的合理配置, 延长食物链, 以最大效率利用 太阳能, 获取优质的农副产品[12]。根据台儿庄区西南部为 连绵起伏的低丘, 北部为平原, 中部和东部较低洼的自然 环境与资源的组合特征的差异, 分别建立不同类型的生态 农业发展模式。

\section{1 低丘建立”林灌草-牧-渔-果-粮”生态农业模式}

台儿庄区的低山丘陵主要分布于本区的西南部, 最高 山峰海拔 $306 \mathrm{~m}$ 。根据丘陵地貌的水土组合特点, 宜采用” 林草-牧-渔-果-粮”生态农业模式。在丘陵顶部和中部适宜 种树、种草, 强化水土保持功能及放牧; 在坡麓地带, 实 行果粮间作, 栽植果树, 在果树间种植粮食作物或油料（以 豆科为主）作物; 丘间谷地通过修建水库, 发展立体养鱼。 通过对丘陵不同海拔梯度的垂直立体开发, 山水林田路的 综合治理, 实现农、林、牧、渔的全面发展。这种立体开 发的每一个环节都发挥着各自的功能并产生不同的效益, 并且各环节之间相互作用、互为促进。

丘顶、丘坡植树、种草。丘顶、丘坡林灌草立体种植， 垂直结构复杂, 可形成较稳定的生态系统, 涵养水源、保 持水土, 为果粮种植及渔业生产提供稳定的生产环境; 并 通过放养牛、羊等家畜为人类提供一定的畜产品, 家畜的 排泄物可成为果、粮生产的有机肥料, 提高土壤肥力, 改 良土壤, 改善农产品的品质。

果、粮间作。果粮之间可互惠共生, 修整高规格的梯 田, 上层栽植各种名优果树, 果木下层间种植粮食作物。 种植的果木既能获取一定的经济效益, 又可保护下层的粮 食作物, 能起到防止风害、保持水土的作用。粮食作物 (豆 科植物）利用其菌根作用, 为土壤固定果、粮生长所需的 氮素营养, 秸杆还田可提高土壤有机质的含量, 提高土壤 肥力, 又反过来促进果木的生长。

丘间谷地可推行立体养鱼。可由相邻的其他生产系统 提供鱼饲草, 进行多鱼种立体混合放养。渔塘肥水可用来 浇灌坡麓地带的果木作物, 塘泥作为肥料可用于肥田, 多 个系统间互惠共生, 形成低丘地区农业生态系统的良性循 环。
4.2 北部平原区推行”种-养-加-沼-贸-旅”一体化的生态农 场

本区平原面积 2.17 万 $\mathrm{hm} 2$, 占全区总面积的 $40.2 \%$, 适 合推行多种形式的”种-养-加-沼-贸-旅”一体化的现代化的 生态农场。这是生态农业系统中的一种组合最多、物质循 环最复杂、功能最齐全的复合生态农业系统类型。其中种 植业和养殖业是生产的基础, 沼气是联系物质循环的枢纽, 加工业是联系种植业和养殖业的桥梁以及系统与外界联系 的窗口, 商贸是各环节产品的商品化, 旅游业是体现这种 农业生态系统的旅游服务功能。该系统中的各个部分都能 充分发挥作用，使系统发挥出极大的效益。

该模式突破了传统农业以种植业为主的特点, 养殖业 和加工业在整个系统中所占的比重较大, ”种-养-加-沼-贸旅”一体化的生态农场的生产结构(如图 1)。

在该生态模式中, 各环节都应依据生态学的原理进行 精心设计, 实行立体种植与立体养殖, 建立相应的农副产 品的深加工企业, 提高农产品的附加值, 可把本区建成区 域最著名的绿色食品生产基地。

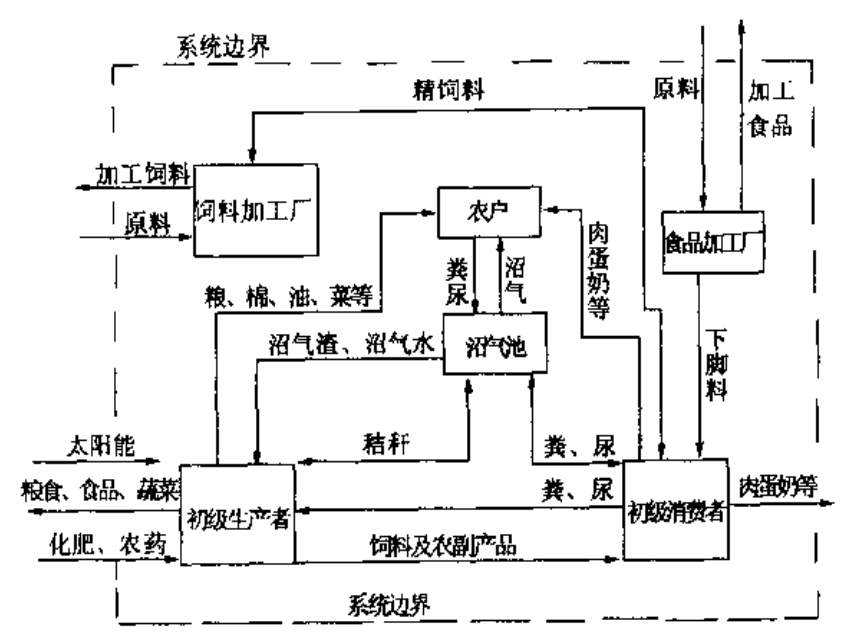

图 1 生态农场模式图

4.3 中部沿运（韩庄运河）滨湖（微山湖）洼地区推行” 基-塘-沼”模式

这是通过食物链各环节的优化组合, 根据生态系统内 能量流动和物质循环规律而设计的一种良性循环的综合生 产体系, 在该系统中, 各生产环节相互利用, 使得系统中 的各种废弃物在生产过程中得到多次增值和循环利用, 既 减少了资源浪费, 又有效地避免了废弃物对环境的污染。 本区中、东部沿运滨湖区域地势低洼, 水患严重, 土壤粘 重, 进行旱作农业难度大且产量低。应因地制宜, 扬长避 短, 在借鉴江南水网地区” 桑基鱼塘”模式的基础上, 根据 
本区域特点, 增加沼气环节, 把低洼地深挖为塘, 把挖出 的泥土覆于四周为基, 塘内养鱼, 基面种植作物, 形成了 一个” 基种桑 (或其他作物), 塘养鱼, 桑叶饲䖯 (其他作物 喂畜), 虫屎喂鱼, 牲畜排泄物入沼气池, 沼气用作能源, 沼渣喂鱼或作基肥, 沼液作为液肥施用, 物质高效循环、 效益显著”的生产格局, 建成”基-塘-沼”式的人工生态系统。

在具体实施过程中, 根据鱼塘周围种植作物的不同, 可以构建稻基鱼塘、菜基鱼塘、果基鱼塘、草基鱼塘和花 基鱼塘等多种模式。实现水陆结合, 鱼 (畜) 桑 (其他作 物) 沼共存, 动植物互惠互利, 相辅相成。该模式应成为 本地区发展生态农业的主要模式之一。

本区域正在实施的”三水”(水稻、水田藕、水产养殖) 特色现代城郊型农业[11], 应实行立体种养, 可作为”基塘-沼” 模式的基础。应延长食物链, 进一步优化结构、丰 富功能, 以创造更大的综合效益, 把本区域打造成为中国 重要的生态农业示范园地、生态农业旅游示范基地。

\section{5. 台儿庄区发展生态农业的保障措施}

\section{1 加强宣传教育, 提高劳动者的生态意识}

生态农业的发展, 首先必须宣传、普及生态意识, 倡导 生态价值观, 使公众特别是领导决策层的观念转变过来, 树立人与人、人与农村环境和谐的生态价值观念。只有改 变原有价值观, 人们的态度和行动才能改变。自觉的生态 意识是发展生态农业的关键。宣传教育应以学校、社会、 家庭教育相结合的方式, 使用多种手段向公众普及生态学 基础知识, 提高农村人口的生态意识水平。将生态意识贯 穿到经济学、社会学、伦理学乃至人们的思想观念、消费 观念、生活方式等各个方面, 推动生态农业的发展。

\section{2 发挥政府的主导作用, 做好服务保障工作}

在普及推行生态农业的过程中, 地方政府应发挥主导 作用, 必须要确立本区发展生态农业模式的主导地位, 加 大对生态农业的支持和推广力度。在生态农业项目引进, 生产用地的流转、租赁, 优惠政策的制订, 技术人员的引 进与培训, 农业企业与农户间的合作等方面, 做好服务保 障工作, 促进本区生态农业的健康稳定地发展。

\section{3 做好农业的基础研究}

生态农业是个系统工程, 需要多学科的通力协作。要 依托当地高校和科研院所科技人员的力量, 加强生态农业 的基础理论研究, 开发设计、推广新的高效率的生态农业 发展模式, 为本区生态农业的发展提供理论保障。

\section{4 做好生态农业的环境治理工作}

农业生产受到环境的强烈影响。近些年来. 受人为活 动影响, 森林过度砍伐, 环境污染加剧等, 使自然灾害加 剧、水土流失、土壤退化等成为影响该地区农业生产和生 态环境的主要因素。需要通过植树造林, 改良土壤, 兴修 水利、搞好农田基本建设等措施对农业生态系统进行人工 调控, 为生态农业发展创设一个良好、稳定的环境。

\section{参考文献(References)}

[1] G. M. Jin, F. Yuan, M. H. Ye, Q. Zhang, and S. F. Liu,, “ Studys on the sustainable development system counstruction of ecological agriculture and is industrial path," Journal of Anhui Agri.Sci.,Vol. 41, No. 24, pp. 10217-10218, August 2013.

[2] Z. Hochman, P. S.Carberry, M. J. Robertson., D. S. Gaydon, L. W. Bell, and P. C. McIntosh, "Prospects for ecological intensification of Australian agriculture," European Journal of Agronomy, Vol. 44, No. 0, pp. 109-123, 2013.

[3] V. Q. Manh, Q. B. Le, and V. P. L. G.Vlek, "Hotspots of human-induced biomass productivity decline and their social-ecological types toward supporting national policy and local studies on combating land degradation," Global and Planetary Change,Vol. 121, No. 0, pp. 64-77, 2014.

[4] M. Ülo, M. Merit, and K. Mart, "Ecological and low intensity agriculture as contributors to landscape and biological diversity," Landscape and Urban Planning, Vol. 46, No. 1-3, pp. 169-177, 1999.

[5] Steven, "Ecological modernization of the agriculture industry in southern Sweden: reducing emissions to the Baltic Sea," Journal of Cleaner Production, Vol. 12, No. 5, pp. 491-503, 2004.

[6] S. M. Luo, "Fundamental classification of eco-agricultural models," Chinese Journal of Eco-Agriculture, Vol.17, No. 3, pp. 405-409, May 2009.

[7] M. Feng, Y. C. Zhou, "A comparative study on the development mode of agricultural circular economy," Rural economy, No. 8, pp.17-20, 2009.

[8] X. Liu, Q. Y. Wang, "THE DEVELOPMENT OF ECOAGRICULTURIAL MODEL IN NEW PERIOD OF CHINA," Economic geography, Vol. 29, No. 8, pp. 1380-1384, August 2009.

[9] H. M. Li, "Study on the development mode of ecological agriculture in southwest mountainous area," Agricultural 
economy, No. 9, pp. 89-91, September 2013.

[10] Y. Li, X. F. Lv, W. M. Yi, Q. Y. Liu, and Y. H. Ao, "Study on energy-flow analysis and assessment of "Four-in-One" energy-ecology model in rural area in the North of China," Renewable Energy Resources, Vol. 27, No. 3, pp. 70-73, Jun 2009.

[11] H. W. Chu, "Ancient river ecological," China territory today, No. 6, pp. 33-38, Jun 2005.
[12] X. B. Duan, X. X. Guo, C. B. Zhou, M. W. Ni, X, L, Yang, and B. Z. Yang, "Discussion on the county eco- agricultural planning design and implementation -- Taking Hubei County of Jingshan Province as an example," Agro-evironmental Protecion,Vol. 11, No. 1, pp. 39-41, 1992. 